\title{
Author Correction: Structural and functional differences in gut microbiome composition in patients undergoing haemodialysis or peritoneal dialysis
}

\author{
Vanessa Stadlbauer(i) ${ }^{1}$, Angela Horvath ${ }^{1,2}$, Werner Ribitsch ${ }^{3}$, Bianca Schmerböck ${ }^{1,2,5}$, \\ Gernot Schilcher ${ }^{3,4}$, Sandra Lemesch ${ }^{1}$, Philipp Stiegler ${ }^{2}$, Alexander R. Rosenkranz ${ }^{3}$, \\ Peter Fickert ${ }^{1}$ \& Bettina Leber ${ }^{1,2,5}$
}

Correction to: Scientific Reports https://doi.org/10.1038/s41598-017-15650-9, published online 15 November 2017

This Article contains an error in the Methods section under the subheading 'Statistics'.

“The sequencing data are available from the European Nucleotide Archive (accession number PRJEB21167).”

should read:

"The sequencing data are available from the NCBI Sequence Read Archive (accession number PRJNA390475)."

(c) (i) Open Access This article is licensed under a Creative Commons Attribution 4.0 International License, which permits use, sharing, adaptation, distribution and reproduction in any medium or format, as long as you give appropriate credit to the original author(s) and the source, provide a link to the Creative Commons license, and indicate if changes were made. The images or other third party material in this article are included in the article's Creative Commons license, unless indicated otherwise in a credit line to the material. If material is not included in the article's Creative Commons license and your intended use is not permitted by statutory regulation or exceeds the permitted use, you will need to obtain permission directly from the copyright holder. To view a copy of this license, visit http://creativecommons.org/licenses/by/4.0/.

(C) The Author(s) 2019

\footnotetext{
${ }^{1}$ Division of Gastroenterology and Hepatology, Department of Internal Medicine, Medical University of Graz, Graz, Austria. 'Division of Transplantation Surgery, Department of Surgery, Medical University of Graz, Graz, Austria. ${ }^{3}$ Clinical Division of Nephrology, Department of Internal Medicine, Medical University of Graz, Graz, Austria. ${ }^{4}$ Intensive Care Unit, Department of Internal Medicine, Medical University of Graz, Graz, Austria. ${ }^{5}$ Center of Biomarker Research in Medicine (CBmed), Graz, Austria. Vanessa Stadlbauer and Angela Horvath contributed equally. Correspondence and requests for materials should be addressed to V.S. (email: vanessa.stadlbauer@ medunigraz.at)
} 